\title{
Renal Replacement Therapy and Kidney Transplantation in Paraproteinemias
}

\section{Sagar Gupta and Thin Thin Maw*}

Division of Nephrology, Washington University School of Medicine in Saint Louis and Barnes Jewish Hospital, Saint Louis, Missouri, USA

\begin{abstract}
Paraproteinemias are systemic disorders which cause renal lesions due to deposition of intact immumoglobulins or immunoglobulin fragments. These diseases are difficult to manage and can lead to end stage renal disease. The advances in the field include newer chemotherapy and hematopoietic stem cells which can reverse renal failure in some cases. This review seeks to provide a greater understanding of the trends and outcomes of renal replacement therapy including kidney transplant in patients with paraproteinemic kidney diseases.
\end{abstract}

Keywords: Paraproteinemias; Renal replacement therapy; Kidney transplantation; Hematopoietic stem cell transplant; Monoclonal gammopathy of undetermined significance

\section{Introduction}

Paraproteinemias are systemic disorders that affect various tissues and organs and are well known to cause renal dysfunction.

\section{Different renal manifestations include}

- Amyloidosis (amyloid light chain [AL], amyloid heavy and light chain $[\mathrm{ALH}]$, amyloid heavy chain $[\mathrm{AH}]$, serum amyloid A [AA])

- Monoclonal immunoglobulin deposition diseases (MIDD; Light-chain deposition disease [LCDD], heavy chain deposition disease, and light and heavy chain deposition disease)

- Light chain cast nephropathy (myeloma kidney)

- Proximal tubulopathy (acquired Fanconi syndrome)

- Monoclonal cryoglobulinemia

- Plasma cell interstitial infiltration and/or interstitial nephritis

In addition, this group of patients is at increased risk of acute and chronic kidney injury from volume depletion, hypercalcemia, hyperuricemia, hyperviscosity, direct toxic effects of medications and contrast exposure. The most frequent causes of end stage renal disease (ESRD) in this setting are myeloma cast nephropathy, light chain amyloidosis (AL) and light-chain deposition disease (LCDD). While newer chemotherapeutic agents (such as bortezomib and lenalidomide) and hematopoietic stem cell transplant offer increased survival, renal impairment continues to be associated with high morbidity and mortality [1-7]. Kidney transplantation can be considered in patients who have undergone successful hematopoietic cell transplantation and have achieved a complete hematologic response. The experience with renal replacement therapy and kidney transplantation in such patients with ESRD is restricted to case series and case reports. This article summarizes the trends and observations of renal replacement therapy in patients with paraproteinemia after review of literature.

\section{Renal Replacement Therapy}

Data on demographics, prognosis and survival in patients with ESRD from amyloidosis, multiple myeloma (MM), LCDD and other monoclonal proliferation disorders remains scarce. As for other causes of ESRD, patients can be treated with hemodialysis or peritoneal dialysis, though hemodialysis appears to be chosen much more frequently [8-10]. Bollee et al. retrospectively studied the outcome of patients with systemic amyloidosis undergoing dialysis [11]. Patients with AL amyloidosis had shorter time from diagnosis to dialysis (25.2 versus $69.3 \mathrm{mo}, \mathrm{P}<0.05)$ and more extrarenal amyloidosis, especially cardiac $(63.2$ versus $5 \%, \mathrm{P}<0.0001)$. Fifteen patients $(78.9 \%)$ with $\mathrm{AL}$ and three patients (15\%) with AA amyloidosis died on dialysis. Median survival was shorter in patients with AL (26 months) than AA amyloidosis $(\mathrm{P}<0.02)$. Prognosis factors for death at 1 year were AL type $(\mathrm{P}<0.01)$, cardiac amyloidosis [odds ratio $(\mathrm{OR})=18, \mathrm{P}<0.01$ ], heart failure $(\mathrm{OR}=8, \mathrm{P}<0.04)$, and shorter time from diagnosis to dialysis (6.1 versus $56 \mathrm{mo}, \mathrm{P}<0.03$ ). Multivariate analysis indicated that AL type $(\mathrm{P}=0.02)$, but not cardiac amyloidosis was independently associated with global mortality. Nasr et al. in their report from the Mayo Clinic [12], observed 22 of 56 (39\%) patients with MIDD progressing to ESRD during a median follow-up of 25 months (range 1-140 months). LCDD with renal manifestations, if untreated, may lead to ESRD [13,14]. In a series of 63 patients with LCDD, the median time to ESRD was 2.7 years, and patient survival was $66 \%$ at 1 year and $31 \%$ at 8 years [15].

Tsakiris et al. published a European Renal Association-European Dialysis and Transplant Association (ERA-EDTA) Registry study in 2010 [2]. Data from 13 national registries consisting of 159,637 patients on renal replacement therapy (RRT) was analyzed. 2453 (1.54\%) had MM or LCDD. The incidence of RRT for ESRD due to MM or LCDD, adjusted for age and gender, increased from 0.70 per million population (pmp) in 1986-1990 to $2.52 \mathrm{pmp}$ in 2001-2005 (increase of 3.6 fold). MM and LCDD patients compared to non-MM patients were older and a higher percentage was on hemodialysis at day 91 after the start of RRT. The most common causes of death in MM and LCDD patients were malignancy $(36.1 \%)$, cardiovascular causes (17.2\%) and infection (14.7\%). MM and LCDD patients had a 2.77 (95\% CI, 2.65-2.90) higher risk of death compared to non-MM patients. The unadjusted median survival on RRT was 0.91 years in MM and LCDD patients and 4.46 years in non-MM patients. Decourt et al. published an analysis on trends in Survival and Renal Recovery in Patients with MM and Light-

*Corresponding author: Thin Thin Maw MD, Division of Nephrology, Assistan Professor of Medicine, Washington University in St Louis, Campus Box 8126, 660 S Euclid Ave. St Louis,MO 63110, USA, Tel: 314-362-8351; Fax: 314-362-2713; E-mail: tmaw@wustl.edu

Received: March 30, 2016; Accepted: April 16, 2016; Published: April 23, 2016

Citation: Gupta S, Maw TT (2016) Renal Replacement Therapy and Kidney Transplantation in Paraproteinemias. J Nephrol Ther 6: 247. doi:10.4172/21610959.1000247

Copyright: ( 2016 Gupta S, et al. This is an open-access article distributed under the terms of the Creative Commons Attribution License, which permits unrestricted use, distribution, and reproduction in any medium, provided the original author and source are credited. 
Chain Amyloidosis on Chronic Dialysis [16]. All incident patients registered in the Renal Epidemiology and Information Network Registry between 2002 and 2011 with ESRD caused by AL amyloidosis, LCDD or myeloma cast nephropathy were included. Of 1459 patients, $265(18 \%)$ patients had AL amyloidosis, $334(23 \%)$ patients had LCDD, and $861(59 \%)$ had ESRD secondary to myeloma cast nephropathy. Renal recovery was observed in only $9.1 \%$ of patients and was improved after 2006. Among 1272 patients who remained on dialysis, 67\% died. Median survival on dialysis was 18.3 months. Main causes of death were malignancies $(34.4 \%)$, cardiovascular diseases (18\%), infections (13.3\%), and cachexia (5.2\%). Iggo et al. in their report of 23 patients with ESRD due to multiple myeloma, illustrated that the patients who survive the first two months, survival is approximately 45 percent at one year and 25 to 30 percent at two to three years [8]. Those who responded to chemotherapy survived significantly longer than those who did not. Korzets et al. outlined similar results with patients responding to chemotherapy with a reduction in light chain production appearing to do much better (mean survival of 47 months versus 17 months in non-responders, p value $<0.05$ ) [9]. On the other hand, Sharland et al. in their retrospective study of 140 patients with multiple myeloma, found no difference in outcomes between patients with severe renal failure, those treated with dialysis, and those with milder renal impairment (median survival, 22 months in both groups), nor was reversibility of renal failure associated with any survival advantage [17].

\section{Kidney Transplantation}

The first kidney transplantation in a patient with ESRD secondary to systemic AL amyloidosis was performed in 1967 [18]. The allograft only functioned for twelve days. Pasternack et al. studied the results of renal transplantation in 45 patients with amyloidosis receiving cadaveric kidney transplant at a single center between March 1973 and October 1981 [19]. Three-year graft survival was similar in the two groups (53 versus 49 percent) with death of patients not included in graft loss, although patient survival was lower in the amyloid group (51 versus 79 percent), predominantly due to infectious and cardiovascular complications. A retrospective study of 25 patients with $\mathrm{AL}$ amyloidosis who underwent kidney transplantation in the UK, revealed median graft survival was 5.8 years with a 5 and 10 -year graft survival of $74 \%$ and $25 \%$ respectively [20]. Both renal and overall outcome in AL amyloidosis are best among patients achieving more than $90 \%$ suppression of the amyloidogenic monoclonal component. The median survival after renal transplantation was 89 months. Tsakiris et al. in their ERA-EDTA study, reported 35 patients with paraproteinemia receiving kidney transplants and their mean survival was 9.6 years [2]. Decourt et al. observed very low rates of kidney transplantation in patients with multiple myeloma or LCDD (2.3\%) [16]. 46 of 1459 patients (3.1\%) were registered on the kidney transplant waiting list after a median of 15 months. 34 (2.3\%) patients received a kidney transplant after a median of 32.5 months on dialysis. Registration on the kidney transplant waiting list was more frequent in patients with AL amyloidosis (7.5\%) than in patients with LCDD (4.5\%) and patients with myeloma cast nephropathy $(1.5 \%$; $\mathrm{P}<0.001)$. Kidney transplant was also more frequent in patients with AL amyloidosis (6.4\%) than in patients with LCDD (3.3\%) and patients with myeloma cast nephropathy $(0.7 \%$; $\mathrm{P}<0.001)$. Median follow-up after kidney transplantation was 32 months. Only one patient lost allograft function after 9 months (she eventually died 8 months after resuming dialysis).

Renal allograft survival is reduced significantly in LCDD patients. Leung et al. retrospectively reviewed the outcomes of 7 patients with LCDD who underwent kidney transplantation [21]. 5 patients were on dialysis before transplantation. LCDD recurred after a median of 33.3 (range, 2 to 45) months in 5 of the 7 patients. One patient remained on dialysis, whereas the other 4 had died. One patient died of progression of multiple myeloma 3 months after kidney transplantation. Only 1 patient remained recurrence free after 13 years with normal renal allograft function.

\section{Hematopoietic Stem Cell Transplant}

Kidney transplantation followed by autologous hematopoietic cell transplantation (AHSCT) offers increased survival in patients with end stage renal disease due to plasma cell dyscrasias [22]. Badros et al. outlined a median survival more than 51 months following AHSCT in 38 patients on hemodialysis [23]. Of note, renal failure had no impact on the quality of stem cell collections and did not affect engraftment. 43 patients with renal insufficiency but not on hemodialysis who received the same treatment had similar survival. Regression of renal damages after 4-5 months from ASCT has been also reported [24]. Several case reports and case series describing patients undergoing successful renal transplantation after hematopoietic cell transplantation can be found [25-29]. Time interval between the two transplants ranges 14.1 months to 4 years. Immunosuppressive therapy consisted of standard 3 drug regimens (calcineurin inhibitor, anti-metabolite and prednisone) to a couple with lenalidomide. There is little experience regarding use of lenalidomide in kidney transplant recipients, therefore, patient should be closely monitored for evidence of infection or the development of malignancy. Acute kidney rejection at 1 month from kidney transplantation was reported in one patient efficiently treated with steroids [22]. Recurrence of light chain deposition 26 months after renal transplantation was also reported [25]. During follow up complete remission and normalization of renal function was observed.

\section{Evolution of MonoclonalGammopathy of Undetermined Significance (Mgus) after Kidney Transplant}

Bancu et al. analyzed the data for renal transplant recipients between 1996 and 2011 [30]. The subjects who presented with MGUS before or after immunosuppressive treatment were selected. Among 587 patients, MGUS was detected in $17(2.9 \%)$ patients. 10 were men and 7 women with a mean age of $69.9 \pm 10.07$ years. Over a median follow-up of 6 years, all patients had a functioning graft. Nine had MGUS before transplantation. One patient had multiple myeloma, and 8 remained stable. Eight patients had development of MGUS after transplantation. Six patients remained stable, 1 showed no MGUS, and 1 displayed an increased monoclonal component in further controls. In conclusion, renal transplantation was not associated with the development of malignant processes in patients with MGUS before transplantation. The group of patients, who developed MGUS after transplantation, had a benign evolution during a 6-year follow-up in their study. Cuéllar-García et al. estimated the incidence of MGUS in kidney transplant recipients and found similar results [31]. Out of 1,016 patients who received a kidney transplant from 1992 to 2012, 16 developed MGUS. The median period of follow up was 30 months. 10 of $16(72.5 \%)$ were more than 50 years old. Two patients developed post-transplantation lymphoproliferative disorders (PTLD). No cases of progression to multiple myeloma or amyloidosis were seen during immune suppression therapy or after. Another study by Naina et al. from Mayo Clinic USA evaluated the long-term outcomes of patients diagnosed with MGUS before or after kidney transplantation [32]. Subjects with multiple myeloma, dysproteinemia-related kidney disease or no pretransplant serum protein electrophoresis were excluded. Of 3,518 patients who underwent kidney transplantation between 
1963 and 2006, MGUS was identified in 42 patients, with 23 before transplant and 19 after transplant. Median follow-up for these patients was 8.5 years (range 0.3-37). 4 (17.4\%) pre-transplant MGUS patients developed a hematologic malignancy: 2 smoldering multiple myeloma and 2 PTLD. None of the 19 patients who developed an MGUS after transplant progressed to multiple myeloma, but 2 (10.5\%) developed Epstein-Barr virus-negative T cell lymphoproliferative disorders at 16 and 26 years after transplant. Median survival was 26.1 and 28.0 years for the pretransplant and posttransplant MGUS groups, respectively. While above studies point to low rates of progression of MGUS after kidney transplantation, transformation to multiple myeloma can occur. Safadi reported 7 cases of multiple myeloma in kidney transplant recipients with cause of ESRD not being monoclonal gammopathy of renal significance (MGRS) [33]. Before transplantation, only 4 out of these 7 patients had protein electrophoresis studies and were diagnosed with MGUS. Median time from kidney transplantation to diagnosis of MM was 72 months (range 3-204 months). The Kidney allograft failed in four patients due to monoclonal protein-related renal disease.

De novo monoclonal immunoglobulin deposition disease is very rare in kidney transplant recipients with very few cases being reported in literature [34-37]. We also need to keep in mind that it can be difficult to assert the de novo character sometimes because serum free light chains, protein electrophoresis studies and/or kidney biopsies are not always performed before transplantation.

\section{Conclusion}

Given therapeutic advances (chemotherapy and stem cell transplant) have been made in the treatment of paraproteinemia, the renal and overall outcome have been improved in current era. Even though randomized controlled trials are lacking to assess the outcome of kidney transplantation in patients with multiple myeloma, several case reports and series showed successful kidney transplants in patients who achieved hematologic response after hematopoietic stem cell transplants. However, further studies are required to determine the optimal timing of the kidney transplant in patients with paraproteinemia.

\section{References}

1. Kumar SK, Dispenzieri A, Lacy MQ, Gertz MA, Buadi FK, et al. (2014) Continued improvement in survival in multiple myeloma: changes in early mortality and outcomes in older patients. Leukemia 28: 1122-1128.

2. Tsakiris DJ, Stel VS, Finne P, Fraser E, Heaf J, et al. (2010) Incidence and outcome of patients starting renal replacement therapy for end-stage renal disease due to multiple myeloma or light-chain deposit disease: an ERA-EDTA Registry study. Nephrol Dial Transplant 25: 1200-1206.

3. Haynes RJ, Read S, Collins GP, Darby SC, Winearls CG (2010) Presentation and survival of patients with severe acute kidney injury and multiple myeloma: $A$ 20-year experience from a single centre. Nephrol Dial Transplant 25: 419-426.

4. Abbott KC, Agodoa LY (2001) Multiple myeloma and light chain-associated nephropathy at end-stage renal disease in the United States: patient characteristics and survival. Clin Nephrol 56: 207-210.

5. Winearls CG (1995) Acute myeloma kidney. Kidney Int 48: 1347-1361.

6. Rota S, Mougenot B, Baudouin B, De Meyer-Brasseur M, Lemaitre V, et al (1987) Multiple myeloma and severe renal failure: a clinicopathologic study of outcome and prognosis in 34 patients. Medicine (Baltimore) 66: 126-137.

7. Chow CC, Mo KL, Chan CK, Lo HK, Wong KS, et al. (2003) Renal impairment in patients with multiple myeloma. Hong Kong Med J 9: 78-82.

8. Iggo N, Palmer AB, Severn A, Trafford JA, Mufti GJ, et al. (1989) Chronic dialysis in patients with multiple myeloma and renal failure: a worthwhile treatment. Q J Med 73: 903-910.

9. Korzets A, Tam F, Russell G, Feehally J, Walls J (1990) The role of continuous ambulatory peritoneal dialysis in end-stage renal failure due to multiple myeloma. Am J Kidney Dis 16: 216-223.

10. Torra R, BladéJ, Cases A, López-Pedret J, Montserrat E, et al. (1995) Patients with multiple myeloma requiring long-term dialysis: presenting features response to therapy, and outcome in a series of 20 cases. $\mathrm{Br} \mathrm{J}$ Haematol 91 : 854- 859.

11. Bollée G, Guery B, Joly D, Snanoudj R, Terrier B, et al. (2008) Presentation and outcome of patients with systemic amyloidosis undergoing dialysis. Clin $\mathrm{J} \mathrm{Am}$ Soc Nephrol 3: 375-381.

12. Nasr SH, Valeri AM, Cornell LD, Fidler ME, Sethi S, et al. (2012) Renal monoclonal immunoglobulin deposition disease: a report of 64 patients from a single institution. Clin J Am Soc Nephrol 7: 231-239.

13. Heilman RL, Velosa JA, Holley KE, Offord KP, Kyle RA (1992) Long-term follow-up and response to chemotherapy in patients with light-chain deposition disease. Am J Kidney Dis 20: 34-41.

14. Sanders PW, Herrera GA (1993) Monoclonal immunoglobulin light chainrelated renal diseases. Semin Nephrol 13: 324-341.

15. Pozzi C, D’Amico M, Fogazzi GB, Curioni S, Ferrario F, et al. (2003) Light chain deposition disease with renal involvement: clinical characteristics and prognostic factors. Am J Kidney Dis 42: 1154-1163.

16. Decourt A, Gondouin B, Delaroziere JC, Brunet P, Sallée M, et al. (2016) Trends in Survival and Renal Recovery in Patients with Multiple Myeloma or LightChain Amyloidosis on Chronic Dialysis. Clin J Am Soc Nephrol 11: 431-441.

17. Sharland A, Snowdon L, Joshua DE, Gibson J, Tiller DJ (1997) Hemodialysis: an appropriate therapy in myeloma-induced renal failure. Am J Kidney Dis 30: 786-792.

18. Belzer FO, Ashby BS, Gulyassy PF, Powell M (1968) Successful seventeenhour preservation and transplantation of human-cadaver kidney. N Engl J Med 278: 608-610.

19. Pasternack A, Ahonen J, Kuhlbäck B (1986) Renal transplantation in 45 patients with amyloidosis. Transplantation 42: 598-601.

20. Pinney JH, Lachmann HJ, Bansi L, Wechalekar AD, Gilbertson JA, et al. (2011) Outcome in renal Al amyloidosis after chemotherapy. J Clin Oncol 29: 674-681.

21. Leung N, Lager DJ, Gertz MA, Wilson K, Kanakiriya S, et al. (2004) Long-term outcome of renal transplantation in light-chain deposition disease. Am J Kidney Dis 43: $147-153$

22. Sánchez Quintana A, Rull PR, Atienza JB, McDonnell CN (2013) Renal transplant in plasma cell dyscrasias with lenalidomide treatment after autologous stem cell transplantation. Nephrology (Carlton) 18: 641-643.

23. Badros A, Barlogie B, Siegel E, Roberts J, Langmaid C, et al. (2001) Results of autologous stem cell transplant in multiple myeloma patients with renal failure. $\mathrm{Br}$ J Haematol 114: 822-829.

24. Nayak, L, Lazarus HM (2013) Renal allografts in plasma cell myeloma hematopoietic cell graft recipients: on the verge of an explosion?. Bone Marrow Transplant 48: 338-345.

25. Barraclough KA, Dowling JP, Schwarer AP, Perry GJ (2007) Sequentia autologous peripheral blood stem cell transplantation and kidney transplantation of light chain deposition disease. Nephrol Dial Transplant 22: 1268-1269.

26. Beitinjaneh A, Burns LJ, Majhail NS (2010) Solid organ transplantation in survivors of hematopoietic cell transplantation: a single institution case series and literature review. Clin Transplant 24: E94-102.

27. Hassoun H, Flombaum C, D'Agati VD, Rafferty BT, Cohen A, et al. (2008) High-dose melphalan and auto-SCT in patients with monoclonal Ig deposition disease. Bone Marrow Transplant 42: 405-412.

28. Khoriaty R, Otrock ZK, Medawar WA, Khauli RB, Bazarbachi A (2006) A case of successful double sequential bone marrow and kidney transplantations in a patient with multiple myeloma. Nephrol Dial Transplant 21: 3585-3588.

29. Herrmann SM, Gertz MA, Stegall MD, Dispenzieri A, Cosio FC, et al. (2011) Long-term outcomes of patients with light chain amyloidosis $(A L)$ after renal transplantation with or without stem cell transplantation Nephrol Dial Transplant 26: 2032-2036.

30. Bancu I, Cañas L, Juega FJ, Pérez M (2015) Outcomes of Monoclonal Gammopathy of Undetermined Significance in Patients Who Underwent Kidney Transplantation. Transplant Proc 47: 2344-2345. 
Citation: Gupta S, Maw TT (2016) Renal Replacement Therapy and Kidney Transplantation in Paraproteinemias. J Nephrol Ther 6: 247. doi:10.4172/21610959.1000247

31. Cuéllar-García C, Sevillano Ruiz-Mateos C, Mazuecos Blanca MA, Narvaez Mejia C, Fernandez Valle MC, et al. (2015) Follow-up monoclonal gammopathy of undetermined significance in kidney transplant. Transplant Proc 47: 78-80.

32. Naina HV, Harris S, Dispenzieri A, Cosio FG, Habermann TM, et al. (2012) LongTerm Follow-Up of Patients with Monoclonal Gammopathy of Undetermined Significance after Kidney Transplantation. Am J Nephrol 35: 365-371.

33. Safadi S, Dispenzieri A, Amer H, Gertz MA, Rajkumar SV, et al. (2015) Multiple myeloma after kidney transplantation. Clin Transplant 29: 76-84.

34. Ecder T, Tbakhi A, Braun WE, Tubbs RR, Myles J, et al. (1996) De novo light- chain deposition disease in a cadaver renal allograft. Am J Kidney Dis 28: 461 465.

35. Tanenbaum ND, Howell DN, Middleton JP, Spurney RF (2005) Lambda light chain deposition disease in a renal allograft. Transplant Proc 37: 4289-4292.

36. Taneda S, Honda K, Horita S, Koyama I, Teraoka S, et al. (2008) Light chain deposition disease after renal transplantation. Am J Kidney Dis 52: 621-625.

37. Balamuthusamy S, Hamrahian M, Zhang R, Batuman V (2009) Myeloma kidney with isolated tubulointerstitial light chain deposition in a renal allograft. Clin Transplant 23: 848-852. 